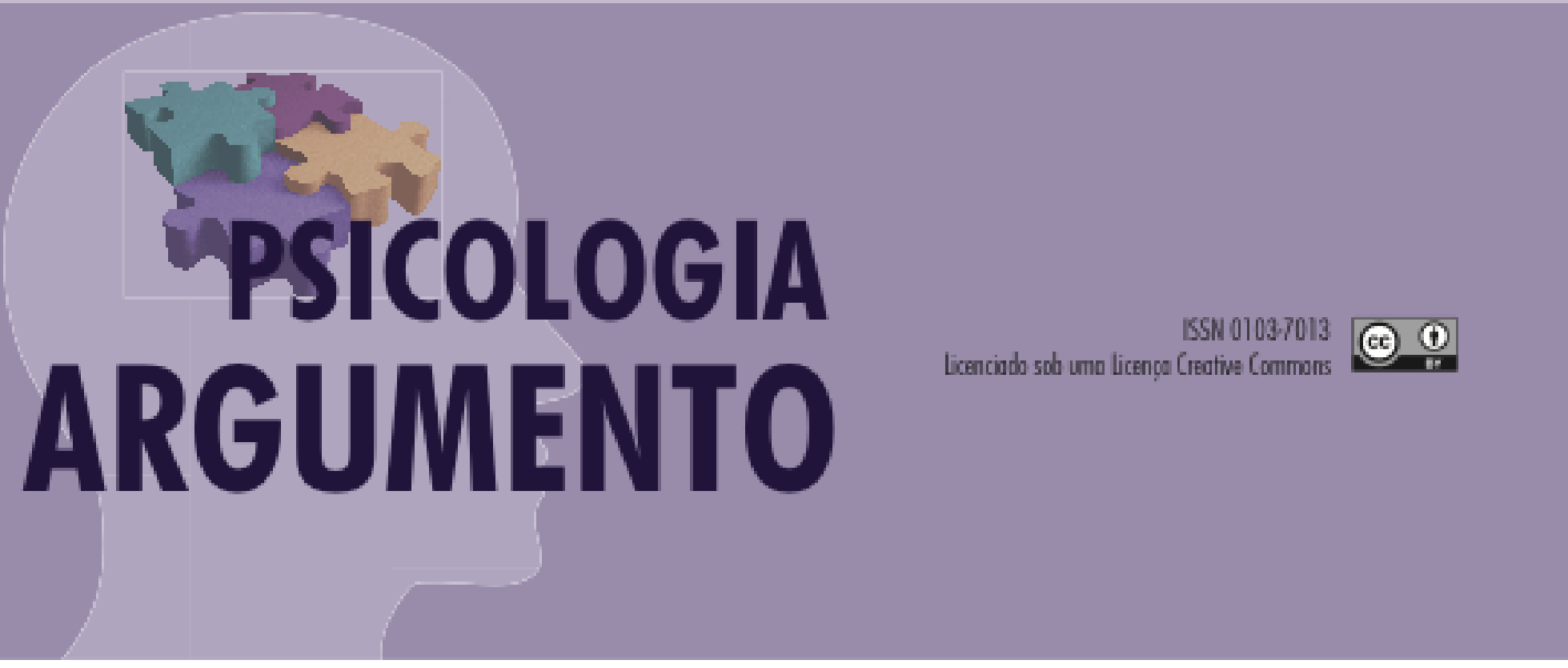

doi $10.7213 /$ psicol.argum.33.082.AO04

\title{
Avaliação psicológica de crianças com deficiência intelectual, vítimas de violência sexual
}

\author{
Psychological evaluation of children with intellectual disabilities, \\ victims of sexual violence
}

Camila Maria dos Santos Muniz [a], Alexandra Ayach Anache [b], Ariállisson Monteiro dos Santos [c]

[a] Graduanda em Psicologia da Fundação Universidade Federal de Mato Grosso do Sul, Campo Grande, Mato

Grosso do Sul, Brasil, camila_muniz9@yahoo.com.br

[b] Professora Titular da Fundação Universidade Federal de Mato Grosso do Sul, Campo Grande, Mato Grosso do

Sul, Brasil, alexandra.anache@gmail.com

[c] Mestrando em Psicologia da Fundação Universidade Federal de Mato Grosso do Sul e do Curso de

Especialização em Avaliação Psicológica do IPOG, Campo Grande, Mato Grosso do Sul, Brasil,

ari.ufms@gmail.com

\section{Resumo}

A avaliação psicológica no contexto jurídico é uma atividade frequente no atendimento aos casos de abuso sexual contra crianças e adolescentes. No entanto, esse trabalho do psicólogo no poder judiciário, voltado às vítimas que possuam algum tipo de deficiência é carente de abordagens na literatura. Com isso, objetivou-se nesta pesquisa caracterizar a avaliação psicológica de crianças com deficiência intelectual, vítimas de violência sexual, mediante entrevista com psicólogos jurídicos atuantes no Fórum Heitor Medeiros, situado no município de Campo Grande/MS. Para isso, uma entrevista semiestruturada foi conduzida junto a três psicólogos que atuam em Vara de Família, Vara da Infância, e Vara da Infância e da Juventude. Com a análise dos dados em caráter qualitativo-descritivo, abordam-se aspectos como a compreensão dos psicólogos sobre a avaliação psicológica no contexto jurídico e os procedimentos do 
processo de avaliação psicológica de crianças com e sem deficiência, envolvidas em denúncias de abuso sexual. Os resultados apontam para as dificuldades verificadas na definição dos profissionais para a prática da Avaliação Psicológica, suas preferências pelo uso da entrevista e às emergências de criação de instrumentos psicológicos para a área jurídica, bem como para as pessoas com deficiência. Sugere-se o aprofundamento na discussão dos limites da prática de avaliação pericial em psicologia e sua forma de contribuição no contexto judiciário. [P]

Palavras-chave: sistema de Justiça; crianças com deficiências; testes psicológicos; defesa da criança e do adolescente.

\begin{abstract}
Psychological evaluation in the juridical context is a frequent activity in attending to cases of sexual abuse against children and adolescents. However, this particular psychologist job in the judiciary, designated to victims who have a disability, is lacking in approaches in the literature. Thus, this study aims to characterize the psychological evaluation of children with intellectual disabilities, victims of sexual violence, through interviews with active juridical psychologists from the Forum Heitor Medeiros, located in Campo Grande / MS. For this purpose, a semi-structured interview was conducted with three psychologists who work in the Family Court, the Childhood Court and the Childhood and Youth Court. The qualitative-descriptive data analysis is used to approach aspects such as psychologists' understanding on psychological evaluation in the juridical context and the procedures of psychological evaluation process of children with and without disabilities, involved in sexual abuse allegations. The results point to the difficulties involved in defining the professionals to the practice of Psychological Evaluation, her preferences for the use of the interview and the need for psychological instruments designated for the juridical department, as well as for people with disabilities. It is suggested to deepen the discussion about the limits of the practical evaluation in psychology and its way of contribution in the judicial context.
\end{abstract}

Keywords: justice system; disability children; psychological tests; child advocacy..

\title{
Introdução
}

A Psicologia Jurídica constitui um campo de atuação recente na história da sociedade. Seu surgimento remonta à década de 50, em Portugal, tendo em sua base as demandas por avaliação psicológica de pessoas envolvidas com questões da Justiça (Costa, Penso, Legnani, \& Sudbrack, 2009). Conforme Rovinski (2002), as atribuições iniciais dos profissionais dessa área, caracteristicamente, estiveram restritas ao âmbito criminal, com estudos focados na investigação de adultos e adolescentes autores de infrações penais.

No Brasil, o reconhecimento da especialidade de psicólogo perito aconteceu em 1964, momento em que nenhum profissional ainda ocupava a posição de servidor do judiciário, contudo, já eram requisitados do contexto clínico para proceder a elaboração de laudos decorrentes de avaliação psicológica das pessoas acusadas pela prática de delitos (Jesus, 2001).

A primeira criação do cargo de Psicólogo, no Poder Judiciário brasileiro, foi propiciada somente na década de 80 por ocasião de concurso público para o Tribunal de Justiça de São Paulo (Bernardi, 1999). Logo, o trabalho do psicólogo deixaria de se limitar à área penal para ser inserido também nos processos de Direito Civil, inicialmente vinculado ao âmbito do Direito da Infância e da Juventude com o então chamado Juizado de Menores que, em 1990, na implantação do Estatuto da Criança e do Adolescente (ECA) passava a ser denominado Juizado da Infância e da Juventude (Lago, Amato, Teixeira, Rovinski, \& Bandeira, 2009).

Justamente com a promulgação da Lei Federal $\mathrm{n}^{\circ} 8.069 / 90$ que versa sobre a criação do ECA, ampliaram-se os espaços do psicólogo no contexto da Justiça (Teixeira, 
1993). Os profissionais da Psicologia passam a ser envolvidos na garantia e consolidação dos direitos da criança, do adolescente e sua família, o que reverbera posteriormente na inserção em outras áreas do direito e assunção de novas atribuições (Bernardi, 1999; Gonzaga, 1999; Brito, 1993), tais como as atividades de orientação, aconselhamento, mediação e participação ativa na articulação de políticas públicas para eficácia do atendimento disponibilizado à população (Conselho Federal de Psicologia [CFP], 2010).

No que se refere à avaliação psicológica no contexto jurídico, Brito (2012) assinala que laudos e pareceres técnico-científicos do psicólogo possuem por finalidade o auxílio na tomada de decisão dos magistrados (Brito, 2012). Esclarece Rovinski (2011) que, nesse sentido, não possui seu foco principal em um caráter assistencial, mas sim da prestação de “[...] informações aos agentes jurídicos sobre questões psicológicas de um sujeito em relação a uma determinada demanda judicial na área cível, criminal ou do trabalho, servindo os dados para subsidiar intervenções do Estado [...]" (p. 95). Essa atuação oculta, consigo, diversas mazelas, sejam relativas aos limites técnicos-científico, éticos ou profissionais.

$\mathrm{O}$ conhecimento desse fato, aliado à prática e ao estudo da primeira autora, tanto nas áreas de Psicologia Jurídica quanto de Psicologia do Desenvolvimento fizeram emergir dúvidas quanto aos conhecimentos sobre o trabalho do psicólogo no poder judiciário em face dos casos de abuso sexual contra crianças e adolescentes que possuam algum tipo de deficiência. Com uma busca preliminar realizada nos bancos de dados SciELO, LILACS, PePSIC e Portal de Periódicos da CAPES, no mês de fevereiro de 2015 com os termos "Avaliação psicológica", "Psicologia Forense", "Perícia psicológica", "Crianças excepcionais", "Crianças com deficiências" e "Violência sexual infantill", todos aplicados isoladamente, obteve-se um total de 500 (quinhentas) pesquisas brasileiras dos últimos 5 anos, nas quais, no entanto, nenhuma se referindo a esses temas em relação.

No processo pericial, os psicólogos jurídicos podem se utilizar de diferentes recursos para investigação, no entanto, Brito (2011) aponta que, frequentemente, verificase a preferência pelo uso das técnicas de entrevista e, exclusivamente delas, ainda quando os psicólogos detenham diferentes recursos para a realização da perícia. Por vez, Silva e Fontana (2011) assinalam que os testes, em especial as escalas e testes projetivos, também podem ser utilizados para embasar os trabalhos de perícias. O que ocorre, tal como lembra Lago et al. (2009), é que nem todos os instrumentos tornam-se adequados para o contexto jurídico.

Serafim e Saffi (2009) descrevem que no cenário brasileiro, para crimes de violência sexual infantil, a perícia psicológica comumente se baseia em cinco procedimentos que são: o estudo dos autos judiciais e demais documentos pertinentes ao caso; a entrevista psicológica; a aplicação de anamnese; a avaliação cognitiva e/ou de personalidade; e, por fim, a análise dos dados obtidos, chegando a conclusões ou encaminhamentos para, então, redigir o laudo psicológico endereçado ao Magistrado. Conforme o objetivo pretendido, sabemos que nesse processo construir as informações necessárias pode impor algumas dificuldades. Nos casos em que o avaliando possua alguma deficiência e, pensemos aqui na deficiência intelectual, devemos levar em consideração que as condições desse sujeito, suas "[...] limitações significativas no funcionamento intelectual e no comportamento adaptativo, que abrange diversas habilidades sociais e práticas cotidianas" (American Association on Intellectual and Developmental Disabilities [AAIDD], 2010) demandam estratégias diferenciadas de abordagem.

Devemos ter em mente que a violência consiste em um fenômeno multifatorial cuja caracterização, muitas vezes, torna-se laboriosa, tal como ocorre quando perpetrada contra 
crianças e adolescentes com deficiência. As modalidades de violência com que podemos nos defrontar são variadas, incluindo-se a violência física, psicológica, as negligências, os abandonos e a violência sexual, mas, sobre essa última, Campos, Paes, Delfino, Queiroz \& Barbosa (2014) ressaltam a grande profundidade das marcas que são deixadas na subjetividade do sujeito que é violentado.

A violência sexual contra a criança e adolescente na forma de conjunção carnal ou pratica de qualquer outro ato libidinoso com menor de 14 (catorze) anos, configura no Código Penal Brasileiro, Art. 217-A (Brasil, 1940), o estupro de vulnerável. Como tal, o parágrafo $1^{\circ}$ do mesmo artigo acrescenta que incorre no mesmo crime quem pratica estas ações com alguém que, por enfermidade ou deficiência mental, é incapaz de discernimento para a prática do ato ou sua defesa (Brasil, 1940). Para esse público, serem contemplados pela lei é um importante instrumento de defesa, mas quando examinamos as condições nas quais as crianças com deficiência intelectual se encontram, nos deparamos com uma posição de grande vulnerabilidade a essas formas de violência, pois se verifica o "[...] lugar histórico de invisibilidade vivido por elas, além da pouca credibilidade dada às suas falas, gestos e comportamentos, sendo na maioria dos casos interpretados como comportamentos disfuncionais ou falas fantasiosas que devem ser coibidas e repreendidas e não acolhidas e compreendidas" (Campos et al., 2014, p. 39).

Em face do conjunto de problemas pertinentes à avaliação pericial de crianças e adolescente com deficiência quando vítimas de abuso sexual e da carência de abordagens sobre o assunto na literatura, torna-se necessário explorarmos se, e de que forma, estas questões se apresentam às práticas profissionais no judiciário diante da primazia de garantia dos direitos da população e dos deveres éticos do psicólogo. Nesse sentido, objetivamos com o presente trabalho caracterizar a avaliação psicológica realizada junto a crianças com deficiência intelectual e que foram vítimas de violência sexual, buscando conhecer quais os procedimentos e recursos empregados por psicólogos jurídicos nessas situações.

Destacamos que, inicialmente, o objetivo do estudo voltava-se para os diferentes tipos de deficiência, no entanto, optamos por focalizar a problematização do tema nos casos de crianças com deficiência intelectual, em decorrência da percepção de que, este público, configura-se como aquele que mais oferece implicações para a forma de avaliação psicológica realizada pelos profissionais entrevistados.

De acordo com o Manual Diagnóstico e Estatístico de Transtornos Mentais, em sua $5^{a}$ edição, (APA, 2014, p. 809), o diagnóstico para a deficiência intelectual leva em questão "[...] a necessidade de uma avaliação tanto da capacidade cognitiva (quociente de inteligência - QI) quanto do funcionamento adaptativo"., pois, os prejuízos às capacidades cognitivas comumente se associam a alterações da atenção, às dificuldades ou distorções de memória e à debilidade das habilidades comunicativas, sociais, de segurança, cuidados pessoais, entre outras.

A etiologia da deficiência intelectual é variável, não havendo consenso entre os pesquisadores para a sua origem. A concordância é a de que, frequentemente, decorre de uma alteração no desempenho do cérebro provocada por fatores que podem ir desde aspectos genéticos até problemas ocorridos durante a gestação ou no parto da criança.

\section{Método}

Nesta pesquisa de abordagem qualitativo-descritiva contamos com a colaboração dos profissionais do Setor Psicossocial do Fórum Heitor Medeiros, unidade jurisdicional autônoma pertencente ao Tribunal de Justiça de Mato Grosso do Sul (TJMS), comarca de 
entrância especial, cuja sede encontra-se na cidade de Campo Grande / Mato Grosso do Sul. O referido fórum atende, exclusivamente, à capital do Estado e possui um Setor Psicossocial, composto por dez profissionais de Psicologia e dezesseis de Serviço Social, os quais trabalham de modo interdisciplinar para o desenvolvimento de estudos psicossociais demandados pelos Magistrados.

Obtivemos a participação de três destes profissionais com base no critério de inclusão adotado que consistiu na existência de alguma experiência anterior dos profissionais de psicologia com caso(s) relativo(s) à violência sexual contra criança ou adolescente com deficiência. São eles: o Psicólogo 1, com mais de quinze anos de exercício em Psicologia Jurídica, lotado na vara de Família; o Psicólogo 2, com cinco anos de experiência, atuante na Vara de Infância e; o Psicólogo 3 que possui sete anos nesta área vinculado à Vara da Infância e da Juventude.

O instrumento utilizado para a coleta de dados foi um roteiro de entrevista semiestruturado, elaborado pelos autores e conduzido de forma individual entre os meses de abril e maio de 2015, em salas reservadas do setor de Psicologia do Fórum Heitor Medeiros. Antes do início das entrevistas, os participantes receberam uma cópia do Termo de Consentimento Livre e Esclarecido (TCLE) assinado por ambos os envolvidos. Cumpre salientar que este projeto de pesquisa foi avaliado e aprovado pelo Comitê de Ética em Pesquisa da Fundação Universidade Federal de Mato Grosso do Sul (UFMS) sob o Parecer de $\mathrm{n}^{\circ}$ 1.031.600. Além disso, foram coletadas as autorizações do Juiz Diretor do Fórum, assim como da Coordenadora-Chefe do Núcleo Psicossocial, no qual os entrevistados desempenham suas funções.

Para condução, a entrevista composta de questões norteadoras, foi dividida em três blocos que versam sobre: a) atuação e avaliação psicológica no contexto jurídico; b) avaliação psicológica em casos de crianças com deficiência vítimas de violência sexual e; c) avaliação psicológica em casos de crianças vítimas de violência sexual que não possuem deficiência. Para a análise das informações obtidas foram estabelecidos três eixos de discussão, os quais versam sobre: a) a definição dos psicólogos sobre a Avaliação Psicológica e as contribuições desta prática para o campo jurídico; b) a prática dos profissionais no que diz respeito à avaliação psicológica de crianças com deficiência, vítimas de violência sexual; e c) eventuais diferenças, ou não, nos atendimentos realizados às crianças que não possuem deficiência.

\section{Resultados}

Os resultados obtidos na presente pesquisa serão apresentados conforme as categorias de análise estabelecidas, sendo elas: a) a definição dos psicólogos sobre a Avaliação Psicológica e as contribuições desta prática para o campo jurídico; b) a prática dos profissionais no que diz respeito à avaliação psicológica de crianças com deficiência, vítimas de violência sexual; e c) eventuais diferenças, ou não, nos atendimentos realizados às crianças que não possuem deficiência.

\section{jurídica}

A definição de Avaliação Psicológica e suas contribuições na área 
No primeiro eixo da entrevista, objetivamos saber qual a compreensão e definição dos profissionais para a área ou prática de Avaliação Psicológica. Estabelecemos esse objetivo na medida em que, antes de conhecermos seus procedimentos para a avaliação psicológica no âmbito jurídico, tornar-se-ia necessário identificar o conhecimento desses psicólogos a respeito de sua prática.

Observamos que as respostas obtidas foram diversas entre os profissionais entrevistados. Ocorreram respostas que discorrem sobre a área com o apoio dos documentos de referência elaborados para a classe e, ainda, com menções a aspectos subjetivos do ser humano atrelados ao contexto social. A pergunta central realizada aos participantes foi: "O que é a Avaliação Psicológica?".

Psicólogo 1: "Você pode lançar mão, principalmente, de entrevistas e quando achar necessário fazer uma complementação, como visita domiciliar, e aplicação de testes. "

Psicólogo 2: “(...) avaliar por meio de entrevista, de recursos reconhecidos (...) pelo Conselho Federal de Psicologia (...) o psiquismo da pessoa, que envolveria entrevistas, testes, (...) crianças em situações lúdicas, (...) visitas domiciliares."

Psicólogo 3: “(...) uma forma de você conhecer, algumas... questões emocionais do sujeito, (...) características de personalidade, a forma como ele vai ta (...) é que é difícil assim, (...) é tão amplo né? (...) acredito que seja mais essa questão de como que ele vai se relacionar também... no meio, né, nas questões é sociais, psicossociais e históricas dele, então você também (...) tem um olhar na avaliação dessa questão do contexto familiar, do contexto social, das relações dele, de trabalho, enfim, mas eu acredito que o foco ainda seja essas questões emocionais e de personalidade dele (...)."

A avaliação psicológica é uma das intervenções utilizadas por psicólogos no âmbito jurídico nas diferentes Varas em que esse profissional pode atuar. Assim, também objetivamos conhecer em que medida os profissionais concebem que esta prática pode fornecer contribuições à Justiça, uma vez que o psicólogo jurídico é profissional presente em casos de disputas de guarda, negligências a crianças e adolescentes, adoções, adolescentes em conflito com a lei e muitos outros.

Com exceção do Psicólogo 1, verificamos que os profissionais se conduzem a respostas pautadas em exemplos de sua própria atuação. No caso do Psicólogo 2, atuante na Vara de Infância, comenta-se das contribuições nos processos de guarda e destituição do poder familiar, e do Psicólogo 3, atuante na Vara da Infância e da Juventude, na compreensão da dinâmica do desenvolvimento de adolescentes autores de um ato infracional. O questionamento ao qual atenderam foi "Quais as contribuições da avaliação psicológica no contexto do judiciário?”. Igualmente, cada uma das respostas obtidas se encontra a seguir.

Psicólogo 1: "Seria subsidiar a decisão do magistrado numa possível sentença. "

Psicólogo 2: "[...] nós abordamos motivação, vínculos afetivos, (...) situações... de avaliação cognitiva, afetiva, (...) questões de agressividade, motivação, inteligência... e situações de (...) conflitos que o juiz (...) precisa (...) entender o que realmente aconteceu e quem poderia (...) exercer com maior equilíbrio psicológico (...) uma demanda. ”

Psicólogo 3: “(...) vou pegar o exemplo da Vara da Infância e Juventude que eu trabalho né, com os adolescentes em conflito com a lei, então você conhecer... um pouco (...) da estrutura daquele (...) sujeito, daquele adolescente, (...) o contexto em que ele está inserido, né, como que (...) são essas relações sociais, emocionais, como que ele lida com os afetos, aí você vai ver a questão da motivação, então eu acredito que tudo isso vai 
favorecer (...) pruma responsabilização daquele ato de uma forma mais assertiva pro adolescente, né... (...) e até também como forma de você fazer um encaminhamento, poder identificar outras áreas, não só responsabilização, mas também a medida de proteção, né, daquele jovem."

\section{Procedimentos utilizados com crianças com deficiência e vítimas de violência sexual}

Com vistas a conhecer como ocorre a perícia psicológica no que se refere a procedimentos junto a crianças com deficiência e vítimas de violência sexual, verificou-se que todos os profissionais entrevistados embasaram suas respostas citando casos aos quais já prestaram atendimento anteriormente, fato que tornou as respostas mais claras e ricas de detalhes acerca dos procedimentos utilizados. Na prática, é possível observar que os psicólogos optam por, inicialmente, conhecer possibilidades de comunicação com a vítima, para então definirem a possibilidade de entrevista. Nota-se, também, que os profissionais mencionaram o contato a locais frequentados pela vítima, além da escuta aos familiares na busca por maiores informações para compor o laudo ou relatório psicológico.

Psicólogo 1: "Situações em que... havendo condição de alguma comunicação (...) você tenta uma entrevista (...) ainda que prejudicada por uma possível deficiência mental leve (...). Ou um surdo mudo você... solicita um (...) tradutor de libras (...) e (...) em casos mais graves (...) que eu já também atendi (...) questão de paralisia cerebral, sem nenhuma possibilidade de comunicação, você pode fazer (...) a entrevista (...) com (...) as pessoas da família, até conseguir chegar numa conclusão se houve ou não houve essa (...) violência sexual, inclusive nas instituições que, porventura, essa criança também seja atendida, vão existir alguns indícios."

Psicólogo 2: "[...] como se tratava de uma adolescente, eu conversei com ela, (...) com os familiares, fui à escola, conversei com o suposto abusador, com o acusado e (...) com (...) outros familiares, pra saber o histórico antes, durante e depois desse relato. E (...) procurei, buscar o maior número possível de (...) informações. Ainda assim, foi muito difícil concluir."

Psicólogo 3: "Eu penso que você tem que escutar as pessoas envolvidas, (...) familiares (...) tentar entender qual que é essa deficiência (...) ver se você tem condições mesmo de poder ter algum tipo de comunicação com a criança, qual que é o grau dessa deficiência, se existe já algum diagnóstico fechado ou não (...) Porque têm algumas deficiências que você consegue estabelecer alguma comunicação, você consegue (...) perceber ou identificar (...) se ela ta compreendendo, se ela tem até uma noção até do porquê que ela está (...) aqui (...) numa avaliação aqui no fórum (...) e ai tem outros casos que (...) fica muito difícil você ter uma abordagem (...) então, acho que inicialmente você tem que entender um pouquinho qual é (...) aquele caso, qual que é a deficiência que a criança ou adolescente tem."

Com o intuito de conhecer sobre a prática da avaliação psicológica de crianças com deficiência e vítimas de violência sexual no que se refere ao uso de instrumentos, perguntamos se, nestes casos, eles se utilizariam de algum teste ou técnica psicológica. Todos os profissionais entrevistados se basearam em suas experiências prévias para sua resposta. Informaram nunca terem utilizado testes psicológicos nas intervenções realizadas, embora tenham feito uso de outras técnicas, tais como desenhos livres e sala 
lúdica, ou de auxílios, como um intérprete de libras durante a entrevista ou, ainda, tenham se valido das informações já apresentadas nos autos judiciais como, por exemplo, relatórios de outras instituições nas quais a criança fora atendida.

Psicólogo 1: “[...] nunca senti a (...) necessidade disso [utilização de testes psicológicos]. Porque eu atendi ou uma pessoa completamente digamos prejudicada nessa possibilidade (...) ou surdo mudo. Que ai você tem a condição da comunicação da entrevista e eram, no caso, adolescentes, então bastava tradução".

Psicólogo 2: "[...] não, porque (...) eu não me lembro se ele tinha cinco ou sete anos... tinha algumas limitações. Mas eu usei desenho livre, (...) sala lúdica (...). ”

Psicólogo 3: "Instrumentos? (...) Bom, tirando a entrevista que eu acho que é a principal (...) instrumento que a gente utiliza na avaliação (...) depende muito da demanda, às vezes você vai avaliar se tem alguma questão de (...) memória (...) aí você pode de repente utilizar (...) algum instrumento nesse sentido (...) de inteligência, às vezes pra você ter uma noção de como que é a questão (...) do entendimento dela (...) da verbalização. Os casos que veio pra mim especificamente (...) geralmente já tava mais ou menos fechado (...) ou pelo menos (...) tava fazendo acompanhamento (...) na APAE ou no CAPS. Mas eu penso que pode ser utilizado pra essas questões... penso né? ”

\section{Eventuais diferenças entre a avaliação de crianças com e sem deficiências}

Uma vez que os psicólogos entrevistados atenderam a ambos os casos de violência sexual, ou seja, aqueles nos quais a vítima possuía uma deficiência e outros em que a vítima não se encontrava nesta condição, os questionamos sobre a existência de diferenças nas avaliações realizadas. Verificou-se que não houve consenso nas respostas dos participantes.

O Psicólogo 1 apresentou afirmação positiva citando a necessidade de zelo adicional na coleta de dados com a vítima a respeito do crime ocorrido e que, quando esta não possui condições de expressão verbal torna-se imperativo um maior empenho, pois é preciso estender a entrevista à família e instituições. Procedimentos que, por vezes, não ocorreriam nos casos em que a vítima não possui deficiência, pois neste, uma única entrevista com a vítima eventualmente forneceria as informações necessárias para a redação do laudo.

Por outro lado, o Psicólogo 2 respondeu negativamente a esta questão, mencionando como única diferença entre os casos a necessidade de adequação de instrumentos psicológicos. Ainda assim, exemplificou que, independentemente da condição em que a vítima se encontre o procedimento usualmente empregado por ele refere-se a entrevistas com familiares ou pessoas de confiança para depois, então, estabelecer o contato com a criança. Condição que torna, de fato, os procedimentos iniciais utilizados em ambos os casos, semelhantes.

Por fim, o Psicólogo 3 também afirmou inexistirem diferenças no atendimento aos dois casos, pois considera que a própria ausência de instrumentos específicos para a área jurídica e, não somente ao público de pessoas com deficiência, gera um trabalho maior na intervenção e conclusão dos casos de violência sexual infanto-juvenil. Contudo, o profissional destacou a técnica da entrevista como recurso útil, tanto quando aplicada à própria vítima nos casos em que esta não possui deficiência, como quando é aplicada aos 
familiares, em casos nos quais a vítima possui dificuldades de comunicação, pois em ambos as informações obtidas por intermédio da entrevista é que irão trazer fundamento ou evidenciar a inexistência deste no crime ocorrido.

\section{Discussão}

A avaliação psicológica é definida pelo Conselho Federal de Psicologia (CFP), em sua Resolução no 07/2003 como “[...] o processo técnico-científico de coleta de dados, estudos e interpretação de informações a respeito dos fenômenos psicológicos, que são resultantes da relação do indivíduo com a sociedade, utilizando-se, para tanto, de estratégias psicológicas - métodos, técnicas e instrumentos".

Santos (2011) comenta que esta definição assinala a contribuição do processo de avaliação psicológica para a compreensão da subjetividade e que, para tanto, os seus resultados devem considerar os condicionantes históricos e sociais da constituição do sujeito e os efeitos destes no psiquismo. Anache (2011) complementa que a avaliação psicológica exige do profissional não somente o manejo de métodos, mas também o conhecimento aprofundado sobre a dinâmica psicológica e, portanto, o domínio das teorias psicológicas.

Ao analisar as afirmativas é possível notarmos expressiva dificuldade dos profissionais na tarefa de definição da prática ou da área de estudo da avaliação psicológica. Como expressado pelos Psicólogos 1 e 2, em que verificamos a tendência em descrevê-la com ênfase nos recursos e instrumentos aplicados à avaliação, mas não quanto à sua finalidade ou dimensões de análise. Esses elementos constitutivos são buscados pelo Psicólogo 3 para explicitar sua compreensão havendo, neste caso, um aparente alinhamento com a definição presente nos documentos de referência para a profissão. Cabe chamarmos a atenção à grande frequência das hesitações ou disfluências presentes nessas falas.

As disfluências denunciam uma dificuldade ocasional na organização do pensamento diante da demanda por uma resposta adequada. Nesses casos, são vários os fatores que podem estar envolvidos desde uma falta de clareza, incertezas ou imprecisões sobre o conceito da Avaliação Psicológica até uma ausência do hábito de realizar essa definição. Não devemos esquecer o fato de que esses profissionais estão inseridos em um órgão jurídico, espaço no qual o zelo adicional para suas afirmativas é de suma importância e, ademais, encontravam-se em uma situação de pesquisa, mas torna-se emergente problematizarmos a gênese dessas dificuldades.

De acordo com Santos (2011), de fato, definir a prática de avaliação psicológica pode ser uma tarefa difícil dado ao recente desenvolvimento da área da Avaliação Psicológica no Brasil. Somam-se a isso as diferentes inserções de sua prática em novos contextos, o que torna essencial a constante atualização do profissional e a atenção do órgão de classe para este problema.

As respostas apresentadas, por vezes, demonstraram a inexistência de um consenso entre os profissionais e, neste cenário, relembramos as críticas sofridas pela área desde seu início, as quais apontam como deficitárias tanto a formação do psicólogo em Avaliação Psicológica, quanto à prática profissional neste campo (Pessoto, 2011). Pessoto (2011) lembra que a avaliação psicológica é prática presente em vários contextos de atuação do 
psicólogo e torna-se essencial, portanto, que o profissional disponha do conhecimento sobre os métodos e técnicas adequados para o contexto em que irá realizá-la.

Com relação aos procedimentos utilizados nos casos de crianças com deficiência, observa-se que, inicialmente, os psicólogos buscam informar-se sobre qual deficiência a vítima possui e o seu grau de desenvolvimento para que, mediante possibilidades de comunicação, possam realizar a entrevista psicológica. Nesse caso, os três profissionais destacam a importância do uso de entrevistas com os familiares das vítimas e contatos com os locais nos quais estas, porventura, frequentam tais como escolas, projetos sociais, instituições e centros de atendimento médico, entre outros, com vistas a obterem maiores informações.

Os psicólogos apontaram como justificativas para o procedimento de coleta de dados junto aos familiares e instituições frequentadas pelas vítimas, tanto a busca por sustentação das informações que ofereçam indícios sobre a ocorrência ou não de um fato quanto a forma pela qual podem obter dados sobre a história pregressa da vítima ou, ainda, questões relacionadas à deficiência e às possibilidades do comparecimento da vítima à entrevista psicológica. Corroboramos que o uso de entrevistas com familiares ou profissionais dos locais frequentados pela vítima é válido na medida em que essa criança ou adolescente pode ter elegido um familiar ou pessoa de sua confiança para verbalizar sobre os fatos.

Adicionalmente, o Psicólogo 1 lembra que na impossibilidade de se estabelecer comunicação com a vítima, por ocasião de deficiência auditiva, o psicólogo pode valer-se de profissionais especializados para viabilizar a entrevista, citando, por exemplo, a presença de um intérprete de Língua Brasileira de Sinais (LIBRAS). Não se soube explicitar se a solicitação de um intérprete cabe ao psicólogo ou ao Poder Judiciário ou, ainda, se o órgão tenha que ser informado sobre essa necessidade. Evidentemente, cabe salientar que nesses casos incorrem outras problemáticas, tais como a morosidade que o pedido poderia acarretar ao processo judicial, já burocrático por natureza, e o fato dessa vítima ter de relatar sobre a experiência traumática pela qual passou a outra pessoa desconhecida, que não somente o psicólogo.

Nessa medida, destacamos a relevância do aprendizado e uso de LIBRAS por parte do psicólogo no atendimento às pessoas com deficiência auditiva, de modo que, além de propiciar respeito às suas diferenças, potencialidades e limitações, a possibilidade de mediação por um profissional de LIBRAS interfere em questões relativas à qualidade da informação e ao sigilo profissional, o que pode acarretar em responsabilidades ao psicólogo. Visando evitar condutas antiéticas torna-se útil a capacitação dos profissionais da Psicologia para favorecer do atendimento a essas vítimas.

O Psicólogo 2 informou sobre uma prática não mencionada pelos outros entrevistados qual seja a condução de entrevista com os supostos agressores do crime. Com relação a essa perspectiva, não há argumentos na literatura da área que impeçam o psicólogo de utilizar-se desse meio desde que as entrevistas ocorram individualmente, visando preservar a vítima do contato e interação com o suposto acusado, evitando-se, assim, maiores prejuízos ao estado emocional da criança ou adolescente. Todavia, cabenos questionar a ocasião e justificativa tanto teórica quanto metodológica para essas estratégias.

Nossos dados corroboram os apontamentos de Brito (2012) e Rovinski (2011) de que no contexto da avaliação pericial exista a preferência dos psicólogos pela utilização de 
técnicas de entrevistas. Da mesma forma, identificamos que suas práticas estejam orientadas a auxiliar o Magistrado em sua tomada de decisões (Brito, 2012; Rovinski, 2011). O que se torna latente é o reconhecimento dos limites nos quais a psicologia pode contribuir para a compreensão dos casos em análise. Portanto, é necessário identificar as condições objetivas da experiência humana para a compreensão dos fenômenos e processos psicológicos, contudo são estes últimos que compreendem os objetos da psicologia. Discutir esse limiar investigativo com o qual a psicologia pode efetivamente contribuir nos processos judiciais, tem nos parecido uma questão oculta para as pesquisas na área.

Todos os entrevistados informaram não terem se utilizado de testes psicológicos no atendimento às crianças com deficiência. Os motivos listados pelos psicólogos foram: a inexistência de possibilidades para que a vítima respondesse ao objetivo do teste ou por optarem pelo uso de outras técnicas, sobretudo, a entrevista, quando havia possibilidades de comunicação; a ausência de testes psicológicos validados para a faixa etária e situação de deficiência da vítima; ou porque o caso já trazia indícios de desfecho devido às informações trazidas pelos familiares e pelos atendimentos realizados anteriormente, por outras instituições, com a vítima, sem acarretar na necessidade de aplicação de testes para, eventualmente, corroborar as questões apresentadas.

Diante das respostas ressalta-se a necessidade de criação de instrumentos psicológicos para as pessoas com deficiência. No que se refere a essa temática, o CFP, no intuito de orientar os profissionais que realizam a avaliação psicológica com este público divulgou, em 2013, uma nota técnica sobre a "Construção, adaptação e validação de instrumentos para pessoas com deficiência”. Nesse documento, o CFP (2013) esclarece que adaptar um teste para a população com deficiência não se refere somente a alterar um aspecto do teste de forma indistinta, vez que, esta atitude pode acarretar em consequências aos procedimentos e resultados do teste, assim como na avaliação psicológica em geral, invalidando-a. Além disso, o órgão salienta que as adaptações podem modificar o constructo que está sendo avaliado.

O CFP (2013) informa que a equipe responsável por desenvolver ou adaptar os testes psicológicos deve, portanto, consultar as pessoas com a(s) deficiência(s) alvo do instrumento, com vistas a avaliar qual o impacto das modificações realizadas em questões tais como usabilidade, acessibilidade, clareza das tarefas, etc. Também recomenda que quando possível, a consulta aos especialistas na área do construto para o qual o teste está sendo adaptado. No que diz respeito à parte prática, o CFP afirma como indispensável que os psicólogos conheçam profundamente sobre o público para o qual o instrumento é destinado, o tipo de deficiência e como esse público poderá manusear os materiais do instrumento, tendo em vista a heterogeneidade da população com deficiência.

Diante de casos em que os instrumentos sejam impróprios ou não esteja condizente com as características particulares do avaliando, o profissional da Psicologia, em qualquer uma de suas áreas de atuação, deve utilizar-se de recursos alternativos desde que reconhecidos oficialmente pelo Conselho da classe, vez que a adaptação de testes não é recomendada sem estudo prévio.

Sobre eventuais diferenças entre os casos de crianças com deficiência e outras que não se encontram nessa condição, nota-se que houve distinções entre os profissionais. $\mathrm{O}$ Psicólogo 1 apresentou uma afirmação positiva exemplificando que nos atendimentos às crianças com deficiência é necessária maior quantidade de procedimentos do que os 
comumente utilizados em atendimentos às crianças que não as possuem. Para tanto, o profissional citou sobre o caso por ele atendido em que a comunicação limitada da criança com deficiência lhe exigia maior atenção na obtenção dos dados. Motivo pelo qual expandiu as técnicas, principalmente, as entrevistas para o contexto familiar da vítima.

O Psicólogo 2 negou que exista diferença no atendimento aos casos. De maneira semelhante exemplificou sua resposta relatando sobre um caso já atendido. Afirmou que poderia, eventualmente, realizar aplicação de testes, porém, em outra circunstância, tal como idade avançada da vítima e, ainda sim, o instrumento teria de ser adaptado, situação não recomendada pelo CFP em vista da possibilidade de serem alterados os resultados do teste, discussão que apresentamos há pouco.

Em contrapartida, nos casos em que a vítima não possui deficiência, o profissional afirmou realizar entrevistas, inicialmente, com uma pessoa de confiança da criança e com a família, depois, com a criança, além de aplicação de testes junto aos pais e o uso de entrevista de anamnese da criança com estes. Observa-se nessa narrativa uma busca do profissional por dados objetivos do caso e não somente na verbalização da vítima. No entanto, embora este psicólogo tenha afirmado a inexistência de diferença na perícia de ambos os casos, salienta-se que os procedimentos por ele citado em casos de abuso sexual infantil (entrevista e aplicação de testes na vítima), muitas vezes não são passíveis de serem realizados em crianças com deficiência. Entende-se, portanto, que embora não esteja expresso na fala do profissional, existem divergências na prática para um e outro caso, se considerarmos os exemplos de técnicas por ele listados.

O Psicólogo 3 afirmou que relativo a testes psicológicos não haveriam diferenças, desde que houvesse uma avaliação do caso recebido e a possibilidade de aplicação de teste a essa vítima. O profissional também entende que seja necessária uma análise por parte do psicólogo se o uso de testes irá de fato trazer informações relevantes aos dados já obtidos. Esse psicólogo também citou sobre a aquisição de elementos do caso com outras pessoas próximas à vítima, retomou a questão sobre o uso de entrevistas como aspecto mais relevante em uma avaliação psicológica e, nos casos em que a vítima possui deficiência, uma forma de propiciar a acolhida a vítima e humanização ao atendimento. $\mathrm{O}$ profissional também mencionou sobre a necessidade de testes para pessoas com deficiência, assunto já explorado neste trabalho e, de maneira semelhante, para a área jurídica. A carência de métodos e técnicas da psicologia, tal como a clareza de como determinadas dimensões podem apoiar o processo de avaliação no contexto pericial, são fundamentais para a ocorrência, ou não, de procedimentos tais quais para a avaliação cognitiva e da personalidade, referidos por Serafim e Saffi (2009).

De acordo com Bernardi (1999), Lago et al. (2009) e Teixeira (1993), diversos avanços ocorreram no campo da Psicologia Jurídica no que diz respeito às práticas dos profissionais, de forma que as atuações se ampliam para além de avaliações psicológicas. O CFP (2010) também afirma que o trabalho do psicólogo na justiça é definido por funções mais abrangentes como aconselhamento, mediação e participação em políticas públicas, no entanto, as práticas apresentadas pelos profissionais entrevistados ainda sinaliza a primazia de suas atividades de perícia psicológica.

\section{Considerações Finais}


A presente pesquisa objetivou caracterizar a avaliação psicológica realizada com crianças com deficiência e vítimas de violência sexual sob o apoio da vivência de psicólogos jurídicos de um fórum na cidade de Campo Grande, tendo a perspectiva de que esses dados possam revelar problemas pertinentes para nossa discussão das práticas de avaliação pericial. Por certo, devemos problematizar os limites ainda existentes para que toda a população possa ser assistida pelo Estado para a garantia de seus direitos e, à psicologia cabe revisar sua capacidade teórica e metodológica para contribuir nessa direção.

Outras pesquisas evidentemente se fazem necessárias, ampliando-se a população de amostra e as temáticas de interface entre a psicologia e o direito. Devemos avançar no esclarecimento da forma como o psicólogo pode responder às demandas do judiciário, corroborar suas conclusões mediante a avaliação das diferentes dimensões psicológicas e elaborar técnicas que se adequem aos objetos pretendidos.

Outras possibilidades se referem à investigação do entendimento que operadores do Direito (juízes, promotores, defensores públicos, advogados) possuem sobre a psicologia, seus recursos e capacidade explicativa para efeito de esclarecimento. Novas pesquisas na área de Psicologia Jurídica com o aprofundamento nessas questões são necessárias para o progresso e melhoria das práticas profissionais no País.

\section{Agradecimentos}

Agradeço aos psicólogos do Fórum Heitor Medeiros que gentilmente colaboraram com a realização deste trabalho.

\section{Referências}

Anache, A. A. (2011). Notas introdutórias sobre os critérios de validação da avaliação psicológica na perspectiva dos Direitos Humanos. In Conselho Federal de Psicologia (Org.), Ano da avaliação psicológica. Textos geradores (pp. 17-20). Brasília: Conselho Federal de Psicologia.

American Association on Intellectual and Developmental Disabilities. (2010). Definition of Intellectual Disability. Recuperado em 29 de setembro de 2015, de http://aaidd.org/intellectual-disability/definition.

American Psychiatric Association. (2014). Manual diagnóstico e estatístico de transtornos mentais (5a ed.). Porto Alegre: Artmed.

Brasil. Lei no 12.015/09, de 07 de agosto de 2009. Congresso Nacional: Brasília. 2009. Disponível em: <http://www.planalto.gov.br/ccivil_03/_Ato2007 2010/2009/Lei/L12015.htm>.

Bernardi, D. C. F. (1999). História da inserção do profissional psicólogo no tribunal de justiça do estado de São Paulo - um capítulo da psicologia jurídica no Brasil. In L. Brito (Org.), Temas de psicologia jurídica (pp. 103-132). Rio de Janeiro: RelumeDumará. 
Brito, L. M. T. (1993). Se-pa-ran-do: um estudo sobre a atuação do psicólogo nas Varas de Família. Rio de Janeiro: RelumeDumará.

Brito, L. M. T. (2011). Avaliação psicológica no contexto das instituições de justiça. In Conselho Federal de Psicologia (Org.), Ano da Avaliação Psicológica. Textos geradores (pp. 85-88). Brasília: Conselho Federal de Psicologia.

Brito, L. M. T. (2012). Anotações sobre a Psicologia Jurídica. Psicologia: Ciência e Profissão, no. spe., (32), 194-205.

Campos, A. A., Paes, D. C., Delfino, J. A., Queiroz, M. A. T., \& Barbosa, R. C. K (2014). Todos pelos direitos: deficiência intelectual, cidadania e combate à violência. São Paulo: APAE de São Paulo.

Conselho Federal de Psicologia. (2010). Referências para a atuação do psicólogo nas varas de família. Brasília: Autor.

Conselho Federal de Psicologia. (2013). Construção, adaptação e validação de instrumentos para pessoas com deficiência. Brasília: Autor.

Costa, L. F., Penso, M. A., Legnani, V. N., \& Sudbrack, M. F. (2009). As competências da psicologia jurídica na avaliação psicossocial de famílias em conflito. Psicologia e sociedade, Brasília, 21(2), p. 233-241. doi:10.1590/S0102-71822009000200010.

Gonzaga, M. T. C. (1999). A atuação da área de Psicologia ao serviço de assistência judiciária de Maringá, Paraná - Brasil [Resumo]. In Anais do III Congresso IberoAmericano de Psicologia Jurídica, (p.104). São Paulo: AIPJ, ABPJ.

Jesus, F. (2001). Psicologia aplicada à justiça. Goiânia: AB.

Lago, V. M., Amato, P., Teixeira, P. A., Rovinski, S. L. R., \& Bandeira, D. R. (2009). Um breve histórico da psicologia jurídica no Brasil e seus campos de atuação. Estudos de Psicologia, 4(26), 483-491. doi: 10.1590/S0103-166X2009000400009.

Pessoto, F. Instituto Brasileiro de Avaliação Psicológica. Ética e Avaliação Psicológica. Recuperado em 09 de setembro, 2015, de http://www.ibapnet.org.br/index.php?cd=23\&descricao=etica_e_avaliacao_psicologic a.

Rovinski, S. L. (2002). La psicologia jurídica em Brasil. In J. Urra (Org.), Tratado de psicologia forense (pp. 661-665). Madrid: SigloVeintiuno de España Editores.

Rovinski, S. L. R. (2011). A avaliação psicológica no contexto jurídico. In Conselho Federal de Psicologia (Org.), Ano da Avaliação Psicológica. Textos geradores (pp. 95-101). Brasília: Conselho Federal de Psicologia.

Santos, A. A. A. (2011). o possível e o necessário no processo de avaliação psicológica. In Conselho Federal de Psicologia (Org.), Ano da Avaliação Psicológica. Textos geradores (pp. 13-16). Brasília: Conselho Federal de Psicologia. 
Serafim, A. P., \& Saffi, F. (2009). Psicologia investigativa nos casos de suspeita de abuso sexual. In B. M. Paulo (Org.), Psicologia na prática jurídica: a criança em foco (pp. 260 272). Niterói: Impetus.

Silva, M. C. R., \& Fontana, E. (2011). Psicologia jurídica: caracterização da prática e instrumentos utilizados. Estudos Interdisciplinares em Psicologia, 1(2), 56-71. doi:10.5433/2236-6407.2011v2n1p56

Teixeira, M. F. (1993). Criação do cargo de psicólogo no poder judiciário: uma luta necessária. In L. Brito (Org.), Psicologia e instituições de direito: a prática em questão (pp. 55-58). Rio de Janeiro: Comunicarte.

Recebido / Received: 28/08/2015

Aprovado / Approved: 28/01/2016 